\title{
The relationship between attitudes towards menarche and current attitudes towards menstruation of women: A comparative study ${ }^{1}$
}

\author{
Nülüfer Erbil ${ }^{2}$ \\ Neslihan Felek ${ }^{3}$ \\ Ebru Karakaşl1 ${ }^{4}$
}

\begin{abstract}
Purpose: The study was conducted to determine affecting factors and to investigate relationship between attitudes towards menarche and current attitudes towards menstruation of women and to compare characteristics of menarche and menstruation of women who were born and raised in the northeastern and western of Turkey.

Method and Materials: This descriptive and comparative study was participated totally 400 volunteer women. The data were collected using a questionnaire containing defined closed and open-ended questions.

Results: The study results showed that women living in Ordu province than women living in Aydin province expressed positive attitudes toward menarche, and the difference was found significant. Nevertheless, attitudes towards current menstruation were similar in both provinces. When the data of 400 women were evaluated together; women's attitudes towards menarche were compared with the current attitudes towards menstruation, and the difference was found statistically significant. Although attitudes of the women towards menarche varied according to where they lived, their current attitudes towards menstruation were similar. In addition, depending upon the province, there were statistically significant differences in women's age at menarche, recollection of menarche, and feelings of shame or happiness at menarche, source and adequacy of information about menstruation, and regularity of their menstrual cycle.

Conclusions: Early menstrual experiences may be related to menstrual experiences later in life and women's attitudes towards menstruation were not affected by geographical locations. In order to develop positive attitudes towards menarche and a woman's future years of menstrual cycles, it is very important that accurate and adequate information for young girls be provided before menarche.
\end{abstract}

Keywords: Menarche; current menstruation; attitude; woman.

\footnotetext{
1 This study was submitted as poster presentation in the $10^{\text {th }}$ Congress of the European Society of Contraception, Prague, Czech Republic, 30 ${ }^{\text {th }}$ April-3 $3^{\text {rd }}$ May, 2008.

2 Ph.D., Assoc. Prof., Ordu University, School of Health, Department of Nursing, Ordu, nerbil@,odu.edu.tr

${ }^{3}$ Nurse, graduated from Ordu University, School of Health, Department of Nursing, Ordu, nslhflk 85@,hotnmail.com

4 Nurse, graduated from Ordu University, School of Health, Department of Nursing, Ordu, smile091985@hotmail.com
} 
Erbil, N., Felek, N., \& Karakaşl1, E. (2015). The relationship between attitudes towards menarche and current attitudes towards menstruation of women: A comparative study. International Journal of Human Sciences, 12(2), 1120-1130. doi:10.14687/ijhs.v12i2.3239

\section{Introduction}

Menarche and menstruation are significant physiological and developmental events in a woman's reproductive capacity and in her life in general (Tortumluoğlu, Özyazıcıoğlu, Tüfekçi, \& Sezgin, 2004; Uskul, 2004). Menarche refers to the adolescent girl's first menstruation (Tang, Yeung, \& Lee, 2003). It represents a concrete symbol in the distinct change from young girlhood to womanhood. Menarche usually occurs suddenly and without precise predictability between the ages 11 and 16 (Özdemir, Nazik, Pasinlioğlu, 2010; Taşkın, 2007). Typically, adolescent girls show negative reactions and feelings to their first menstrual period (Woods, Dery, \& Most, 1982). They define their feelings with terms such as "scared", "upset", "worried" or "ashamed". Studies of adult women's recollections of menarche often confirm these negative feelings (Woods, et al., 1982; Erbil, Orak, \& Bektaş, 2010). Menstruation is defined as the "periodic vaginal discharge of bloody fluid from the nonpregnant uterus that occurs from the age of puberty to menopause" (Bobak, \& Jensen, 1993). Menstruation is a normal physiological process, however, it may be viewed either positively or negatively in different cultures (Kalman, 2003; do Amaral, Hardly, \& Hebling). Positive attitudes may prevail if the menses are viewed as a sign of femininity, fertility, youth, or purification of the body. On the other hand, negative perceptions associated with being vulnerable and susceptible to different illnesses can create feelings of disgust and shame (Kalman, 2003). Studies about menarche in Turkey showed that between $44 \%$ and $80 \%$ of women reacted to menarche with mostly negative feelings (Tortumluoğlu et al., 2004; Karadağ, Dinç, \& Özcan, 1999; Taşç1, 2006; Erbil, \& Türkcan, 2008).

Previous studies abroad have revealed that there is a relationship between attitudes towards menarche and emotional reactions and experiences of first menstruation and attitudes towards menstruation during adulthood (Koff, \& Rierdan, 1996; McPherson, \& Korfine, 2004). Other previous studies of menarche and menstruation in Turkey studied emotional reactions, the level of knowledge, menstrual symptoms and menstruation hygiene habits ( Karadağ et al., 1999; Erbil, \&Türkcan, 2008; Erdoğan, Işık, \& Saruhan, 1991; Yazıc1, \& Kobya, 1999; Musal, \& Uçku, 1993). Results of these studies showed no specific findings regarding the relationship between women's current attitudes toward menstruation and the attitudes toward their first menstruation. Therefore, the findings of this study are important. This study explored the aforementioned relationship, if any, and further researched whether there was a difference between menarche and menstruation attitudes of women living in two different regions of Turkey. The results of this study will provide a resource in the health care services for midwives, nurses and other health care professionals. It is 
Erbil, N., Felek, N., \& Karakaşl1, E. (2015). The relationship between attitudes towards menarche and current attitudes towards menstruation of women: A comparative study. International Journal of Human Sciences, 12(2), 1120-1130. doi:10.14687/ijhs.v12i2.3239

also hoped that these study results will stimulate and influence the development of future education and curriculum planning, as well as further research into this topic.

\section{Purpose}

The study was conducted to determine affecting factors and to investigate relationship between attitudes towards menarche and current attitudes towards menstruation of women and to compare characteristics of menarche and menstruation of women who were born and raised in Aydin and Ordu provinces in the northeastern and western of Turkey.

\section{Method and Material}

\subsection{The place and time of the study}

This research was made in Aydın and in Ordu provinces of Turkey between 15th February 2007- 25th May 2007

\subsection{Population and sample selection}

Two hundred-three women from Ordu province and 197 women from Aydın province of Turkey who volunteer with selection criteria were recruited to sample of this study with convenience method. Ordu province is located in the northeastern Black Sea region of Turkey, and aydin province is in the western Aegean region of Turkey. A convenience sample of women was recruited to this study Aydın province has a warmer climate than Ordu province.

The inclusion criteria for study participants were: the women had to be still menstruating; they had to be born and raised in Ordu and Aydin provinces in Turkey; and they had to be willing to take part in the study.

\subsection{Type of study}

The research was a descriptive and comparative study.

\subsection{Data collection}

Data were collected using a questionnaire prepared by the researchers that included questions regarding women's socio-demographic characteristics $\left(1^{\text {st }}-5^{\text {th }}\right.$ questions $)$, their knowledge, attitudes and behaviors towards menarche, menstruation $\left(6^{\text {th }}-14^{\text {th }}\right.$ questions $)$ and their current menstruation characteristics $\left(15^{\text {th }}-19^{\text {th }}\right.$ questions) (Tortumluoğlu et al., 2004; Karadağ et al., 1999; Koff, \& Rierdan, 1996; McPherson, \& Korfine, 2004; Yazıc1, \& Kobya, 1999). The questionnaire was pilot-tested on 20 volunteer women and it was found acceptable. The first part of the questionnaire form was about their age, education level, occupation, income, and family type. The second part of the questionnaire form included their menarche age, recollection status of menarche 
Erbil, N., Felek, N., \& Karakaşl1, E. (2015). The relationship between attitudes towards menarche and current attitudes towards menstruation of women: A comparative study. International Journal of Human Sciences, 12(2), 1120-1130. doi:10.14687/ijhs.v12i2.3239

day, feelings at menarche, whether dysmenorrhea at menarche, attitude about menarche, source of information, information about menstruation before menarche and adequacy of information about menstruation. The third part of the form contained questions about the regularity of the current menstrual cycle, menstrual bleeding flow, attitude about present menstruation, whether dysmenorrhea is experienced with current menstruation and attitude towards current menstruation. All the postpartum women in the sample completed the questionnaire using face to face interview techniques. The questionnaire form filled out the questionnaire took approximately 10 to 15 minutes.

\subsection{Limitations of the study}

This study had some limitations. These limitations: sample of this study was recruited with convenience method; the findings are based on self-report; the questionnaire about menarche and menstruation attitudes and experiences were developed by the researchers of this study and after pilot test was performed. These might affect the results of the study.

\subsection{The generalizability of the study}

Due to limitations of this research and findings can generalize only to this sample.

\subsection{Research ethics}

The women were invited to participate in the study and researchers gave them all pertinent information before verbal consent was obtained. They were also advised that the study would pass through an ethical approval protocol and that they would not be paid for their participation in the study. The researchers guaranteed participants that their identities and answers would be kept confidential. This study was approved Health Directorate of the province, and the study conformed to the principles of the Declaration of Helsinki.

\subsection{Evaluation of data}

Descriptive statistics including frequency, percentage, mean, minimum, maximum, standard deviation were calculated. Differences were tested with Chi-square test and the $\mathrm{t}$ test. The Chisquare test and t test was used to compare characteristics and attitudes towards menarche and menstruation of women. The data were analyzed using the SPSS for Windows version 11.5. The significance level of the test was targeted at 0.05 .

\section{Results}

Two hundred-three women from Ordu province and 197 women from Aydin province of Turkey agreed to take part in this study. The average age of participants was $30.8 \pm 8.5$. The study participants ranged in age from 18 to 45 years. In this study, 95.3\% of women had attended primary 
Erbil, N., Felek, N., \& Karakaşl1, E. (2015). The relationship between attitudes towards menarche and current attitudes towards menstruation of women: A comparative study. International Journal of Human Sciences, 12(2), 1120-1130. doi:10.14687/ijhs.v12i2.3239

school and higher education, and $54.8 \%$ of them were housewives. In this group $72.3 \%$ of the women were living in a smaller family (see Table 1). The current average monthly income was 1044.0 $\pm 665.1 \mathrm{TL}$.

Table 1. Distribution of participants from Ordu and Aydin provinces $(n=400)$

\begin{tabular}{lcccccr}
\hline & \multicolumn{1}{c}{ Aydin province } & \multicolumn{3}{c}{ Ordu } & province & \multicolumn{2}{c}{ Total } \\
\cline { 2 - 7 } Variables & $\mathbf{n}$ & $\mathbf{\%}$ & $\mathbf{n}$ & $\mathbf{\%}$ & $\mathbf{n}$ & $\mathbf{\%}$ \\
\hline Education & & & & & & \\
$\quad$ Illiterate & 16 & 8.1 & 3 & 1.5 & 19 & 4.7 \\
$\quad$ Primary school & 72 & 36.5 & 46 & 22.7 & 118 & 29.5 \\
$\quad$ Secondary school & 43 & 21.8 & 40 & 19.7 & 83 & 20.8 \\
$\quad$ High school & 37 & 18.8 & 65 & 32.0 & 102 & 25.5 \\
$\quad$ University & 29 & 14.7 & 49 & 24.1 & 78 & 19.5 \\
Occupation & & & & & & \\
$\quad$ Clerck & 39 & 19.8 & 55 & 27.1 & 94 & 23.5 \\
$\quad$ Worker & 32 & 16.2 & 22 & 10.8 & 54 & 13.5 \\
$\quad$ Self-employed & 12 & 6.1 & 21 & 10.3 & 33 & 8.2 \\
$\quad$ Housewife & 114 & 57.9 & 105 & 51.7 & 219 & 54.8 \\
Family type & & & & & & \\
$\quad$ Nuclear & 150 & 76.1 & 139 & 68.5 & 289 & 72.3 \\
Big & 42 & 21.3 & 46 & 22.7 & 88 & 22.0 \\
$\quad$ Big family in some times & 5 & 2.5 & 18 & 8.9 & 23 & 5.7 \\
& & & & & & \\
\hline
\end{tabular}

The study results showed that $33 \%$ of women living in Ordu province and $16.3 \%$ of women in Aydin province expressed positive attitudes toward menarche, and the difference was found significant $(\mathrm{p}=0.000) .88 .2 \%$ of women living in Ordu province and $93.4 \%$ of women in Aydin province expressed positive attitudes toward present menstruation. Nevertheless, attitudes towards current menstruation were similar in both provinces $(\mathrm{p}=0.071)$. While more women in Aydin province felt a sense of shame $(60.8 \%)$ at menarche, a feeling of happiness at menarche $(67.7 \%)$ was more common for women living in Ordu province. The findings concerning fear at menarche, the belief or thinking that menstruation is not really necessary, and women's ambivalent feelings were similar both in Ordu and in Aydın province. The rate of women who received information about menstruation before menarche was $86.8 \%$ in Aydin and $79.3 \%$ in Ordu, and the difference was significant $(\mathrm{p}=0.046)$. The first source of information about menstruation in both provinces was mothers. The information received about menstruation was reported as adequate by $74 \%$ of women living in Aydın province and 47.6\% of women living in Ordu province (see Table 2). 
Erbil, N., Felek, N., \& Karakaşl1, E. (2015). The relationship between attitudes towards menarche and current attitudes towards menstruation of women: A comparative study. International Journal of Human Sciences, 12(2), 1120-1130. doi:10.14687/ijhs.v12i2.3239

Table 2. Comparison of variables and distrubition according to menarch and menstruation characteristics of participants from Aydin province and Ordu province $(n=400)$

\begin{tabular}{|c|c|c|c|c|c|c|c|}
\hline \multirow[b]{2}{*}{ Variables } & \multicolumn{2}{|c|}{ Aydın province } & \multicolumn{2}{|c|}{ Ordu province } & \multicolumn{2}{|c|}{ Total } & \multirow[b]{2}{*}{$\mathrm{p}$} \\
\hline & $\mathrm{n}$ & $\%$ & $\mathrm{n}$ & $\%$ & $\mathbf{n}$ & $\%$ & \\
\hline \multicolumn{8}{|l|}{ Attitude at menarche } \\
\hline Positive & 32 & 16.3 & 67 & 33.0 & 99 & 24.8 & \\
\hline Negative & 165 & 83.7 & 136 & 67.0 & 301 & 75.3 & $0.000 * * *$ \\
\hline \multicolumn{8}{|l|}{ Feelings at menarche $*$} \\
\hline Fear & 111 & 52.9 & 99 & 47.1 & 210 & 52.5 & $0.129 * * *$ \\
\hline Shame & 79 & 60.8 & 51 & 39.2 & 130 & 32.5 & $0.001 * * *$ \\
\hline Happiness & 32 & 32.3 & 67 & 67.7 & 99 & 24.7 & $0.000 * * *$ \\
\hline Ambivalent feelings & 11 & 73.3 & 4 & 26.7 & 15 & 3.7 & $0.057 * * *$ \\
\hline Unnecessary of menstruation & 8 & 36.4 & 14 & 63.6 & 22 & 5.5 & $0.214 * * *$ \\
\hline \multicolumn{8}{|l|}{ Dysmenorrhea at menarche } \\
\hline Yes & 74 & 37.6 & 89 & 43.8 & 163 & 40.8 & \\
\hline No & 123 & 62.4 & 114 & 56.2 & 237 & 59.2 & $0.222^{* * *}$ \\
\hline \multicolumn{8}{|l|}{$\begin{array}{l}\text { Information about } \\
\text { menstruation before menarche }\end{array}$} \\
\hline Yes & 171 & 86.8 & 161 & 79.3 & 332 & 83.0 & \\
\hline No & 26 & 13.2 & 42 & 20.7 & 67 & 17.0 & $0.046 * * *$ \\
\hline \multicolumn{8}{|l|}{$\begin{array}{l}\text { Source of information about } \\
\text { menstruation }(n=337)^{* *}\end{array}$} \\
\hline Mother & 120 & 69.4 & 93 & 56.7 & 213 & 63.2 & \\
\hline Friend & 30 & 17.3 & 57 & 34.8 & 87 & 25.8 & \\
\hline Teacher & 12 & 6.9 & 4 & 2.4 & 16 & 4.7 & \\
\hline Mass media & 8 & 4.6 & 2 & 1.2 & 10 & 3.0 & $0.000 * * *$ \\
\hline Other & 3 & 1.7 & 8 & 4.9 & 11 & 3.3 & \\
\hline \multicolumn{8}{|l|}{$\begin{array}{l}\text { Adequacy of information about } \\
\text { menstruation }(\mathrm{n}=337) * *\end{array}$} \\
\hline Yes & 128 & 74.0 & 78 & 47.6 & 206 & 61.2 & \\
\hline No & 21 & 12.1 & 29 & 17.7 & 50 & 14.8 & \\
\hline Partially & 24 & 13.9 & 57 & 34.7 & 81 & 24.0 & $0.000 * * *$ \\
\hline \multicolumn{8}{|l|}{ Recollection of menarche } \\
\hline Yes & 93 & 47.2 & 141 & 69.5 & 234 & 58.5 & \\
\hline No & 104 & 52.8 & 62 & 30.5 & 166 & 41.5 & $0.000 * * *$ \\
\hline \multicolumn{8}{|l|}{ Regularity of menstrual cycle } \\
\hline Regular & 76 & 38.6 & 145 & 71.4 & 221 & 55.2 & \\
\hline İrregular & 121 & 61.4 & 58 & 28.6 & 179 & 44.8 & $0.000 * * *$ \\
\hline \multicolumn{8}{|l|}{ Attitude present menstruation } \\
\hline Positive & 184 & 93.4 & 179 & 88.2 & 363 & 90.8 & \\
\hline Negative & 13 & 6.6 & 24 & 11.8 & 37 & 9.2 & $0.071 * * *$ \\
\hline \multicolumn{8}{|l|}{$\begin{array}{l}\text { Dysmenorrhea at current } \\
\text { menstruation }\end{array}$} \\
\hline Yes & 53 & 26.9 & 71 & 35.0 & 124 & 31.0 & \\
\hline No & 144 & 73.1 & 132 & 65.0 & 276 & 69.0 & $0.81 * * *$ \\
\hline \multicolumn{8}{|l|}{ Menstrual bleeding flow } \\
\hline Hypermenorrhea & 24 & 12.2 & 30 & 14.8 & 54 & 13.5 & \\
\hline Normal & 153 & 77.7 & 140 & 69.0 & 293 & 73.3 & $0.114 * * *$ \\
\hline Hypomenorrhea & 20 & 10.1 & 33 & 16.2 & 53 & 13.2 & \\
\hline Menarche age of women (year) & \multicolumn{2}{|c|}{$12.94 \pm 1.28$} & \multicolumn{2}{|c|}{$13.30 \pm 1.32$} & \multicolumn{2}{|c|}{$13.13 \pm 1.31$} & $0.008 * * * *$ \\
\hline
\end{tabular}


Erbil, N., Felek, N., \& Karakaşl1, E. (2015). The relationship between attitudes towards menarche and current attitudes towards menstruation of women: A comparative study. International Journal of Human Sciences, 12(2), 1120-1130. doi:10.14687/ijhs.v12i2.3239

The rate of recollection of menarche among women living in Ordu province $(69.5 \%)$ was higher than that for women living in Aydin province (47.2\%). Although the ages of the women living in both provinces were similar, regularity of their menstrual cycles was found to be different $(\mathrm{p}=0.000)$. Women from Aydin province experienced menarche at an earlier age than women from Ordu province (respectively, 12.9 years and 13.3 years) and the difference was found significant (see Table 2).

This study compared the following variables of two provinces, and the differences were found statistically significant; attitudes towards menarche $(\mathrm{p}=0.000)$; feelings at menarche of shame $(p=0.001)$ and happiness $(p=0.000)$; information about menstruation before menarche $(p=0.046)$; source of information about menstruation $(\mathrm{p}=0.000)$; information received before menarche about menstruation considered "adequate" ( $p=0.000)$; recollection of menarche $(p=0.000)$ and regularity of menstrual cycles $(p=0.000)$; and age at menarche $(p=0.008)$. The present study compared the living province of woman with their feelings of fear, ambivalent emotions, views that menstruation is unnecessary, dysmenorrhea at menarche, attitude towards present menstruation, dysmenorrhea at present menstruation, menstrual bleeding type, and the differences were not found significant $(\mathrm{p}>0.05)$ ( see Table 2).

The data of totally 400 women were evaluated and analyzed; $24.8 \%$ of the women had positive attitudes towards menarche, and $90.8 \%$ of them had positive attitudes towards their current menstruation. Women's attitudes towards menarche were compared with the current attitudes towards menstruation, and the difference was found statistically significant $(p=0.014)$.

\section{Discussion}

Menarche is the most important biological event in the life of women and is a marker towards achieving maturity and the onset of reproductive capability for many adolescent females (Şenol, Gündüz, \& Öztürk, 2010). Beliefs about menstruation are acquired at an early age, and these beliefs usually reflect the general cultural stereotypes about menstruation as a negative and symptom-laden phenomenon (Woods et al., 1982). Accurate and adequate information about menstruation is seen as an important factor in developing a young girl's positive response towards menarche and her subsequent menstrual cycles (Çıtak, \& Terzioğlu, 2002).

In the study, the attitude towards menarche of women who received information about menstruation before experiencing menarche was found to be more positive. Women who were older at their first menstruation had a more positive attitude towards menarche, and the difference was found significant. Similar to previous studies the present study revealed that most of the 
Erbil, N., Felek, N., \& Karakaşl1, E. (2015). The relationship between attitudes towards menarche and current attitudes towards menstruation of women: A comparative study. International Journal of Human Sciences, 12(2), 1120-1130. doi:10.14687/ijhs.v12i2.3239

women experienced negative emotions such as fear, shame, ambivalent feelings or the belief that menstruation is unnecessary (Tang et al., 2003; Erbil,\& Türkcan, 2008; Chrisler, \& Zittel, 1998). Only one-quarter of the women (24.8\%) experienced menarche as a positive happening in their lives. The present study showed that the percentage of women who had obtained information about menstruation before menarche was $83 \%$, however, just $61.2 \%$ of women thought that the information was sufficient. Other studies on this subject indicate that the percentages of women who had received information about menstruation before their first period ranged from $14.6 \%$ to 97.9\% (Tortumluoğlu et al., 2004; Musal, \& Uçku, 1993).

Tortumluoğlu et al. (2004) revealed that the information levels about menstruation before the menarche of young girls was very low in a rural area of the eastern part of Turkey (14.6\%), and the findings of another study were similar to this study. We thought that this difference resulted from differences in culture and living in different regions of Turkey. Previous studies have reported that the main sources of information about menstruation were mothers, friends, schools and the media, but disseminating information to young girls about menstruation was not enough (Erbil et al., 2010; Erbil, \& Türkcan, 2008; Koff, \& Rieardan, 1996). Previous studies have emphasized that women who are better prepared for the first menstruation showed less negative reactions to menarche, menstrual symptoms, and body image issues than women who were less well prepared (Koff, \& Rieardan, 1996; Çıtak, \& Terzioğlu, 2002; Rierdan, Koff, \& Stubss, 1989). In accordance with the available literature, the present study found that at menarche many women experienced strong negative emotions. Unfortunately, the preparation of young girls for menarche and these new changes in their bodies and reproductive capacity is not adequate. One study emphasized that the later menstrual attitudes of women who had experienced early menstrual periods were negative. In fact, they were more negative than women with positive experiences at menarche, and the relationship was related to their health behaviors and body image issues (McPherson, \& Korfine, 2004). Koff \& Rierdan (1996) reported that early adolescent girls' premenarcheal expectations and postmenarcheal experiences were associated with longer-term menstrual experiences.

We found that there were differences in the women born and raised in Aydin or Ordu provinces in their attitudes towards menarche, but it did not affect their attitude towards their current menstruation status (see Table 2). Also, the average age at menarche for women living in Aydin province in the western of Turkey (12.9 \pm 1.2 years) was one year younger than the mean age of menarche in women living Ordu province (13.3 \pm 1.3 years) in northeastern Turkey, (see Table 2). We found the attitude towards menarche of women living in Ordu province to be more positive than those in Aydin province. Perhaps this was because the onset of menarche for women of Ordu 
Erbil, N., Felek, N., \& Karakaşl1, E. (2015). The relationship between attitudes towards menarche and current attitudes towards menstruation of women: A comparative study. International Journal of Human Sciences, 12(2), 1120-1130. doi:10.14687/ijhs.v12i2.3239

province came later than the women of Aydin province. The arrival of menarche for the women of Aydin province was accompanied more often by a sense of shame than women of Ordu province. At the same time, we discovered that women in Aydin province received more information before menarche than women in Ordu province. Nevertheless, mothers remained the primary source of information in both provinces. Although the women living in the two provinces were of similar age, the regularity of their menstrual cycles was significantly different. However, attitudes towards their current menstruation were relatively the same for the women of both Aydin and Ordu province. The age at which young girls reach menarche is known to be influenced by genetic factors, environmental conditions, body size and physique, socioeconomic variables, and level of education (Sharma, Talwar, \& Sharma, 1988; Georgiadis, Mantzoros, Evagelopolou, \& Spentzos, 1997; Ersoy, Balkan, Günay, Onă̆, \& Egemen, 2004).

Studies in Turkey and abroad have reported the average age at menarche between 12 years and 13.9 years (Tortumluoğlu et al., 2004; Ersoy et al., 2004; Tavares, Haeffner, Barbieri, Bettiol, Barbieri, Souza, 2000; Mimoun, Le, Buhler, Costa, \& Hosansky, 2001; Ayatollahi, Dowlatabadi, Ayatonahi et al., 2003 Bekar, \& Güçsavaş, 1990). Aydın province has a warmer climate than Ordu province. The difference in the mean age at menarche between the two provinces is thought to be caused by differences in climate. The mean age at menarche of all women (13.1 \pm 1.3$)$ in this study was evaluated, and it was found to be similar to the current available literature (Tortumluoğlu et al., 2004; Tavares et al., 2000; Ayatollahi et al., 2003; Bekar, \& Güçsavaş, 1990).

\section{Conclusions and recommendations}

In conclusion, we found that menarche experiences of women are associated with menstrual experiences later in life. Although attitudes of the women towards menarche varied according to where they lived, their current attitudes towards menstruation were similar. In addition, depending upon the province, there were variations in women's age at menarche, recollection of menarche and feelings of shame or happiness at that time, source and adequacy of information about menstruation, and regularity of their menstrual cycle.

Results suggest that early menstrual experiences may be related to menstrual experiences later in life. In order to develop positive attitudes towards menarche and a woman's future years of menstrual cycles, it is very important that accurate and adequate information for young girls be provided before menarche. Midwives, nurses and other health professionals fill a very important role in providing full and accurate information about menarche and menstruation to young girls 
Erbil, N., Felek, N., \& Karakaşl1, E. (2015). The relationship between attitudes towards menarche and current attitudes towards menstruation of women: A comparative study. International Journal of Human Sciences, 12(2), 1120-1130. doi:10.14687/ijhs.v12i2.3239

who may become mothers of the future. This much-needed support can help develop a positive and healthy attitude towards this normal body function.

\subsection{Usability of study results}

It is hoped that the present study will encourage further research related to menstruation and women's reproductive health, psychological health and other health issues.

\subsection{Acknowledgements}

The authors would like to thank all participants of this study. This study was submitted as poster presentation in the $10^{\text {th }}$ Congress of the European Society of Contraception, Prague, Czech Republic, 30 $0^{\text {th }}$ April- $3^{\text {rd }}$ May, 2008. The data of both provinces had been evaluated together in submitted the poster presentation. However, data of this study according to reviews were reanalyzed and the data of two provinces were compared and discussed.

\section{References}

Ayatollahi, S.M., Dowlatabadi, E., \& Ayatonahi, S.A. (2003).Age at menarche in Iran. Annals Human Biology, 29(4), 355-362.

Bekar, M., \& Güçsavaş, N. (1990). Determination of knowledge about menstruation hygiene and reactions to menarche of senior girl students in primary education in Sivas province. 2. National Nursing Congrees Book, İzmir. (in Turkish)

Bobak, I.M., \& Jensen, M.D.(1993). Maternity \& Gynecologic Care. Missouri: Mosby-Year Book Inc, 1993.

Chrisler, J.C., \& Zittel, C.B. (1998). Menarche stories: Reminiscences of college students from Lithuania, Malaysia, Sudan and United States. Health Care for Women International, 19(4), 303312.

Çıtak, N, \& Terzioğlu, F. (2002). Knowledge and practices about primary dysmenorrhea of girl students at Abant Izzet Baysal University. Health and Society, 12(3), 69-79 (in Turkish).

do Amaral, M.C., Hardly, E., \& Hebling, E.M. (2011) Menarche among Brazilian women: memories of experiences. Midwifery, 27(2), 203-208.

Erbil, N., Orak, E., \& Bektaş, A.E. What are mothers knowing about sexual education, how much are mothers giving sexual education to their daughters? International Journal of Human Sciences, 2010, 7(1), 66-83. (in Turkish)

Erbil, N., \& Türkcan, C. (2008). Knowledge, attitude and behaviors of secondary school students about menstruation. Nursing Forum, 11(1), 74-78 (in Turkish).

Erdoğan, E., Issık, A., \& Saruhan, A.(1991). A study about menstrual cycle characteristics and menarche experiences of adolescent girls. Ege Üniversitesi Hemsirelik Yüksekokulu Dergisi, 7, $31-46$ (in Turkish).

Ersoy, B., Balkan, C., Günay, T., Onağ, A., \& Egemen, A.(2004). Effects of different socioeconomic conditions on menarche in Turkish female students. Early Human Development, 76(2), 115-125. 
Erbil, N., Felek, N., \& Karakaşl1, E. (2015). The relationship between attitudes towards menarche and current attitudes towards menstruation of women: A comparative study. International Journal of Human Sciences, 12(2), 1120-1130. doi:10.14687/ijhs.v12i2.3239

Georgiadis, E., Mantzoros, C.S., Evagelopolou, C., \& Spentzos, D.(1997). Adult height and menarcheal age of young in Greece. Annals Human Biology, 24(1), 55-59.

Kalman, M.(2003). Taking a different path: menstrual preparation for adolescent girls living apart from their mothers. Health Care for Women International, 24 (10), 868-879.

Karadağ, N., Dinç, G., \& Özcan, C. (1999). Determination of knowledge, attiude and behaviors about menstruation hygiene. Nurse, 49(1-3), 37-39 (in Turkish).

Koff, E., Rierdan, J. (1996). Premenarcheal expectations and postmenarcheal experiences of positive and negative menstrual related changes. Jornal of Adolescent Health,18(4), 286-291.

McPherson, M.E., \& Korfine, L. (2004). Menstruation across time: menarche, menstrual attitudes, experiences, and behaviors. Womens Health Issues, 14(6), 193-200.

Mimoun, S., Le, M.G., Buhler, M., Costa, A., \& Hosansky, F. (2001). The experience of menstruation and disorder in 603 women using contraception in 1999. Gynecologie Obstetriquie \& Fertile, 29(6), 452-453.

Musal, B., \& Uçku, R.(1993). Menarche and menstruation characteristics among adolescent girl students. Health and Society, 3(2), 21-24 (in Turkish).

Özdemir, F., Nazik, E., \& Pasinlioğlu, T. (2010). Determination of the motherly reactions to adolescents experience of menarche. Journal of Pediatric Adolescent Gynecology, 23(3), 153-157.

Rierdan, J., Koff, E., \& Stubss, M.L. (1989). Timing of menarche, preparation, and initial menstrual experience: Replication and further analysis in a prospective study. Journal of Youth and Adolescence 18(5), 413-426.

Sharma, K., Talwar, I., \& Sharma, N. (1988). Age at menarche in relation to adult body size and physique. Annals of Human Biology, 15(6), 431-434.

Şenol, V., Gündüz, E., \& Öztürk, A.(2010). Attitude, behavior and knowledge regarding menarche and menstruation in adolescent schoolgirls in Kayseri. Turkiye Klinikleri Journal of Gynecology Obstetrics, 20(2), 77-83.

Tang, C.S., Yeung, D.Y., \& Lee, A.M. (2003). Psychosocial correlates of emotional responses to menarche among Chinese Adolescent Girls. Journal of Adolescent Health, 33(3), 193-201.

Taşkın, L. (2007). Physiology of reproductive system. In Taşkın, L. (Eds.), Maternity and Gynecologic Nursing. Ankara: Sistem Ofset Publishers. (in Turkish)

Tavares, C.H., Haeffner, L.S., Barbieri M.A., Bettiol, H., Barbieri M.R., \& Souza, L.(2000). Age at menarche among schoolgirls from a rural community in Southeast Brazil. Cadernos de Saude Publica, 16(3), 709-715.

Tortumluoğlu, G., Özyazıcıoğlu, N., Tüfekçi, F., \& Sezgin, S. (2004). The description of emotional reaction and age at menarche in a rural areas. Journal of Anatolia Nursing and Health Sciences, 7(2), 76-88. (in Turkish)

Uskul, A. K. (2004). Women's menarche stories from a multicultural sample. Social Science Medicine, 59(4), 667-679.

Woods, M. F., Dery, G.K., \& Most, A.(1982). Recollections of menarche, current menstrual attitudes, and perimenstrual symptoms. Psychosomatic Medicine, 44 (3), 285-293.

Yazic1, S., \& Kobya, H. (1999). Attitudes with menstrual hygiene menstruation perceptions of girl students in student hostels of Karadeniz Technical University, VII. National Nursing Congress Book, Erzurum. (in Turkish) 